\section{A propósito de un caso clínico: mujer con gastroenteritis aguda}

\section{About a clinical case of a woman with acute gastroenteritis}

\author{
Ana M. ${ }^{a}$ González Picazo ${ }^{1 * *}$ \\ Leire Muñoz Gallego' \\ Carmen Martín Salinas ${ }^{2}$
}

1. Estudiante de 4. ${ }^{\circ}$ curso. Grado en Enfermería. Universidad Autónoma de Madrid (UAM). Madrid. España.

2. Profesora de Enfermería. Facultad de Medicina. Universidad Autónoma de Madrid (UAM). Madrid. España.

*Autor para correspondencia.

Correo electrónico: anamariag8@hotmail.es (Ana M. González Picazo).

Recibido el 26 de agosto de 2019; aceptado el 23 de septiembre de 2019.

\section{RESUMEN}

Se presenta el caso de una paciente de 80 ańos, afectada de una gastroenteritis aguda de 2 semanas de evolución en posible relación con un cuadro viral. La causa principal es la infección transmitida por alimentos y superficies contaminadas, que en personas de edad avanzada supone un riesgo para su vida debido a la deshidratación. Por ello, será fundamental una reposición de líquidos oral e intravenosa, además de una introducción temprana de alimentación sólida. La valoración de las respuestas de la paciente se ha realizado a partir de los requisitos de autocuidado de Dorothea Orem.

La evolución ha sido favorable, y en el periodo de una semana se redujeron las deposiciones en frecuencia y características favoreciendo así la restauración de la piel perianal, se sustituyó la fluidoterapia con reposición de electrolitos por hidratación oral, y la dieta astringente pasó a dieta basal, con buena tolerancia.

PALABRAS CLAVE: Autocuidado, deshidratación, diarrea, dieta, equilibrio hidroelectrolítico, fluidoterapia, gastroenteritis, heces, infección.

\section{ABSTRACT}

We present here the case of an 80 old female patient, affected by an acute gastroenteritis of two weeks of evolution in possible relation with a viral case. The main cause is infection transmitted by food and contaminated surfaces. Therefore, an oral and intravenous fluid replacement will be essential, as well as an early introduction of solid nutrition. The assessment of the patient's responses was based on the self-care requirements of Dorothea Orem.

The evolution has been favorable and in a period of one week the depositions in frequency and characteristics were reduced favoring the restoration of the perianal skin, fluid therapy has been replaced with the replacement of electrolytes by oral hydration, and the astringent diet has passed a basal diet, with good tolerance.

KEYWORDS: Dehydration, diarrhea, diet, feces, fluid therapy, gastroenteritis, infection, self care, water-electrolyte balance.

\section{- INTRODUCCIÓN}

El cuidado de una paciente con gastroenteritis aguda (GEA) de larga evolución implica una atención integral, puesto que la pérdida rápida de líquido y electrolitos puede provocar una deshidratación aguda y debilidad generalizada que impida el desempeño de las actividades básicas de la vida diaria (ABVD). La GEA ${ }^{1}$ es un problema de salud inferior a las 2 semanas de evolución y caracterizada por diarrea, acompañada o no de vómitos, dolor abdominal y/o fiebre, frecuente en personas de edad avanzada. La causa principal es la infección en el $80 \%$ de los casos, fundamentalmente por Norovirus, Salmonella, Shigella y Clostridium difficile ${ }^{2}$, transmitidos por los alimentos, el agua y las superficies contaminadas, así como directamente de persona a persona ${ }^{3}$. En general, se resuelve sin tratamiento en 1 a 3 días, excepto en situaciones graves y en personas de edad avanzada, donde requiere una actuación más precisa ${ }^{4,5}$. Inicialmente se suspende la ingestión oral de alimentos, que se reanuda precozmente cuando disminuye la frecuencia y el número de deposiciones y se ha comprobado la tolerancia oral, por el efecto trófico sobre el enterocito 6 . En general, se utiliza una dieta astringente, aunque no hay estudios que confirmen su eficacia. La única restricción consensuada es la exclusión de la leche por la malabsorción de la lactosa secundaria al proceso inflamatorio 5 .

\section{- HISTORIA CLÍNICA}

Mujer de raza blanca, de 80 ańos, que ingresa en el servicio de medicina interna procedente de urgencias por gastroenteritis de 2 semanas de evolución. El cuadro se inició con 5-6 deposiciones diarias de consistencia blanda-líquida, que aumentaron a 7-8, de aspecto amarillento con dolor abdominal difuso. A su llegada a planta después de pasar 2 días en urgencias, la paciente presenta buen estado general, disminución del número de deposiciones a 3-4 diarias, de mayor consistencia y ausencia de dolor abdominal.

\section{EXPLORACIÓN}

En la analítica realizada en urgencias se observan unos niveles séricos de sodio, potasio y cloruro por debajo del rango normal. También se realizó un coprocultivo con resultado negativo. La radiografía de abdomen y el electrocardiograma son normales. 


\section{- PLAN DE ACTUACIÓN}

La atención de enfermería fundamentada en el proceso de atención en cuidados garantiza la calidad de los mismos y contribuye a reducir la probabilidad de que aparezcan complicaciones, realizando una valoración exhaustiva que permita identificar el estado hídrico, principal causa de morbimotalidad 6 .

Este proceso de cuidado se inicia con la recogida de datos y valoración. De acuerdo con Marcos Espino ${ }^{7}$, la valoración mediante la teoría del autocuidado permite a la enfermera disponer de una visión integral de las demandas y necesidades de cuidado del paciente con GEA, dado que este problema de salud puede durar, como indica Cuevas ${ }^{8}$, entre 4 días y 2 semanas. Continúa con la identificación de diagnósticos en- fermeros ${ }^{9}$, la selección de criterios de resultados $(\mathrm{NOC})^{10} \mathrm{y}$ de intervenciones $(\mathrm{NIC})^{11}$, para finalizar con la planificación individualizada de actividades y la evaluación de todo el proceso, utilizándose el modelo de autocuidado de $\mathrm{Orem}^{12}$.

\section{Valoración}

Se realiza el día del ingreso ${ }^{13}$ y está resumida en la tabla 1.

\section{Diagnóstico}

- Déficit de autocuidado: baño e inodoro; rc debilidad y deterioro para acceder al bańo/inodoro (levantarse y sentarse) y realizar el aseo.

Tabla 1. Valoración de la Agencia de Autocuidado

\begin{tabular}{|c|c|}
\hline $\begin{array}{l}\text { Factores } \\
\text { condicionantes } \\
\text { básicos }\end{array}$ & $\begin{array}{l}\text { Viuda. Vive con una hija, yerno y nietos } \\
\text { En casa colabora con su hija en algunas tareas domésticas. Todos los días da un paseo a media mañana acompañada por una amiga. Lleva una } \\
\text { alimentación sana, aunque bebe poca agua a pesar de las indicaciones de su familia. Duerme unas 5-6 horas, pero se levanta descansada }\end{array}$ \\
\hline \multirow{3}{*}{$\begin{array}{l}\text { Estado general de } \\
\text { salud }\end{array}$} & Diagnosticada de angina de pecho estable, insuficiencia cardiaca, hipertensión arterial y dislipemia desde hace 8010 años \\
\hline & $\begin{array}{l}\text { Tratamiento prescrito: ranolazina } 500 \text { mg, ácido acetilsalicílico } 100 \text { mg, atenolol } 50 \text { mg, amlodipino } 5 \text { mg y atorvastatina } 20 \text { mg. } \\
\text { Buena adherencia }\end{array}$ \\
\hline & $\begin{array}{l}\text { FC: } 80 \text { pulsaciones/min; PA: } 110 / 77 \mathrm{mmHg} ; \mathrm{T}^{\text {a. }}: 35,9^{\circ} \mathrm{C} \text { y } \mathrm{StO}_{2}: 97 \% \text { basal } \\
\text { IMC: } 30,11 \mathrm{~kg} / \mathrm{m}^{2} \text {. Refiere pérdida de peso de unos } 3-4 \mathrm{~kg} \text { porque la ropa le queda grande } \\
\text { Cribado nutricional con el MUST: riesgo bajo de desnutrición. Piel perianal íntegra, aunque irritada y enrojecida. Vía venosa periférica } \\
\text { en MSI sin signos de flebitis }\end{array}$ \\
\hline $\begin{array}{l}\text { Mantenimiento de } \\
\text { un ingreso suficiente } \\
\text { de aire }\end{array}$ & $\begin{array}{l}\text { Ritmo respiratorio regular, ausencia de tos, expectoración o ruidos respiratorios. No precisa de oxigenoterapia ni de ayudas técnicas en } \\
\text { la ventilación } \\
\text { Buena coloración de piel y mucosas }\end{array}$ \\
\hline $\begin{array}{l}\text { Mantenimiento } \\
\text { de una ingesta } \\
\text { suficiente de } \\
\text { líquidos }\end{array}$ & $\begin{array}{l}\text { Bien hidratada. Refiere consumir unos } 4 \text { vasos de agua al día, además de té en el desayuno y en la merienda, en total unos } 1000 \text { cc de } \\
\text { líquido. No presenta problemas en la deglución de líquidos }\end{array}$ \\
\hline \multirow{4}{*}{$\begin{array}{l}\text { Mantenimiento } \\
\text { de una ingesta } \\
\text { suficiente de } \\
\text { alimentos }\end{array}$} & Buena tolerancia a la dieta basal. Algo inapetente. No náuseas ni vómitos \\
\hline & $\begin{array}{l}\text { Valoración alimentaria: } \\
\text { - Desayuno completo, refiriendo que por la mañana es cuando tiene más apetito } \\
\text { - Comida, se toma todo el primer plato y algo más de la mitad del segundo porque no le gusta demasiado } \\
\text { - Merienda, se toma solo la infusión } \\
\text { - Cena, solo ingiere algo del primer plato, por inapetencia }\end{array}$ \\
\hline & Tiene prótesis dental, en buenas condiciones \\
\hline & No requiere asistencia en la alimentación \\
\hline $\begin{array}{l}\text { Provisión de } \\
\text { cuidados asociados } \\
\text { con los procesos de } \\
\text { eliminación }\end{array}$ & $\begin{array}{l}\text { Eliminación urinaria. Micción espontánea en cuña, 6-7 veces al día. Orina clara, aunque escasa } \\
\text { Eliminación intestinal. Deposición en cuña, 3-4 veces al día de consistencia semilíquida/blanda }\end{array}$ \\
\hline $\begin{array}{l}\text { Mantenimiento del } \\
\text { equilibrio entre la } \\
\text { actividad y el reposo }\end{array}$ & $\begin{array}{l}\text { Dependiente para las actividades básicas de la vida diaria relativas al acceso al baño e inodoro durante la estancia hospitalaria } \\
\text { Sentada en el sillón toda la mañana. Necesita ayuda para acostarse } \\
\text { Disminución de la fuerza muscular. Ha estado } 2 \text { semanas sin moverse prácticamente nada por la gastroenteritis y la pérdida de líquidos } \\
\text { y electrolitos } \\
\text { Presenta sensación de rigidez y pérdida generalizada de tono muscular } \\
\text { Duerme unas 5-6 horas. Se despierta unas dos veces durante la noche por la elevada temperatura de la habitación, pero vuelve a } \\
\text { dormirse a los } 15 \text { minutos }\end{array}$ \\
\hline
\end{tabular}


Tabla 1. Valoración de la Agencia de Autocuidado (cont.)

\begin{tabular}{l|l}
$\begin{array}{l}\text { Mantenimiento } \\
\text { del equilibrio } \\
\text { entre soledad y la } \\
\text { interacción social }\end{array}$ & $\begin{array}{l}\text { Convive con una hija. Se siente satisfecha con su actual rol de jubilada, mantiene una conversación amena. Antes del comienzo de la } \\
\text { GEA era independiente en las ABVD, desempeñando las labores de la casa sin problema, contando con la ayuda de su familia } \\
\text { Recibe visitas de familiares } \\
\text { Utiliza gafas para leer. Tiene alguna dificultad para la audición } \\
\text { Está orientada en las tres esferas, mostrando una actitud abierta y mirando directamente a los ojos durante la entrevista }\end{array}$ \\
\hline $\begin{array}{l}\text { Piel perianal íntegra eritematosa } \\
\text { Ligero edema en miembros inferiores, desde los tobillos hasta el primer tercio de ambas piernas, sin presencia de fóvea ni lesiones } \\
\text { cutáneas. No presenta dolor al tacto o presión. No se aprecian signos de trombosis venosa profunda }\end{array}$ \\
$\begin{array}{l}\text { Prevención de } \\
\text { peligros para la vida, funcionamiento y } \\
\text { el bienestar humano }\end{array}$ & $\begin{array}{l}\text { No presenta riesgo de caídas porque no deambula en el momento de la valoración } \\
\text { Escala de Norton 16. Riesgo mínimo de úlceras por presión }\end{array}$ \\
\hline $\begin{array}{l}\text { Sufre hipoacusia moderada utilizando audífonos desde hace } 5 \text { años } \\
\text { Se preocupa de manera normal por su estado de salud y su aspecto físico }\end{array}$ \\
\hline $\begin{array}{l}\text { Promoción del } \\
\text { funcionamiento y } \\
\text { desarrollo humano }\end{array}$ & Acepta su situación de salud actual, pero quiere recuperarse y volver a su domicilio \\
\hline
\end{tabular}

ABVD: actividades básicas de la vida diaria; FC: frecuencia cardiaca; GEA: gastroenteritis aguda; IMC: índice de masa corporal; MSI: miembro superior izquierdo; PA: presión arterial; St02: saturación tisular de oxígeno.

Tabla 2. Problema de colaboración: riesgo de desequilibrio hidroelectrolítico

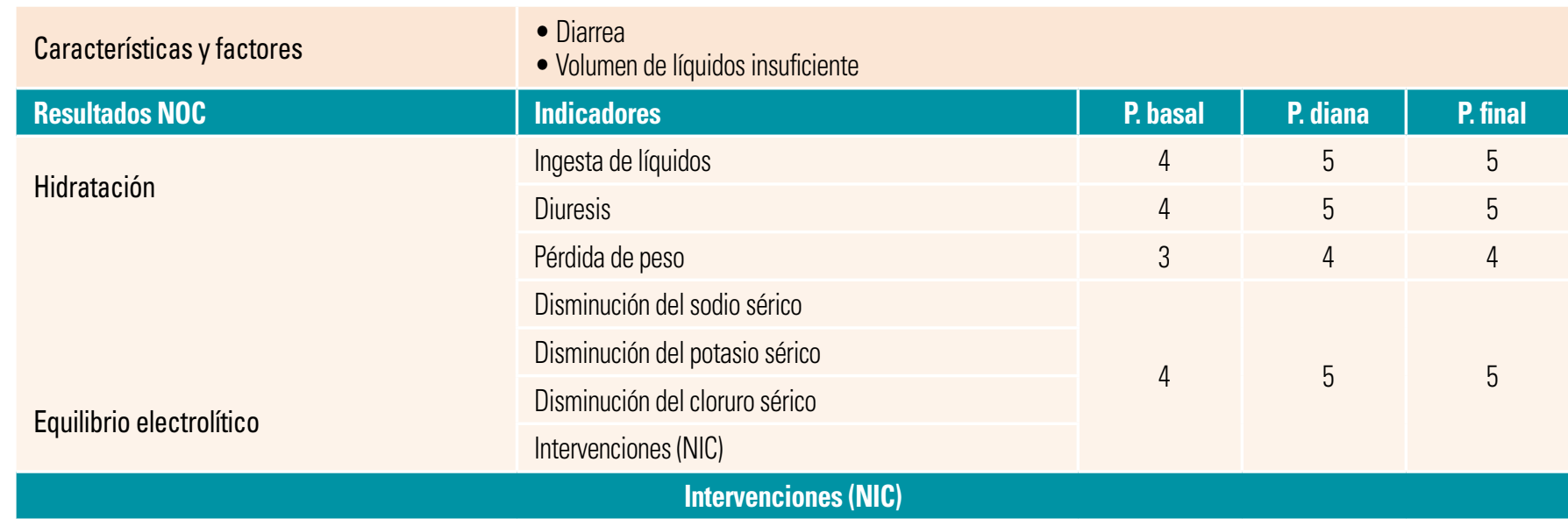

Monitorización y manejo de líquidos/electrólitos

- Valoración de electrolitos séricos

- Administrar suplementos de electrolitos adecuados al desequilibrio del paciente

- Observar signos de retención de líquidos

- Observar la fuerza muscular

Diagnóstico enfermero: deterioro de la integridad cutánea perianal

\begin{tabular}{|c|c|c|c|c|}
\hline Características y factores & - Diarrea & & & \\
\hline Resultados NOC & Indicadores & P. basal & P. diana & P. final \\
\hline \multirow{3}{*}{ Integridad tisular: mucosa perianal } & Eritema & 2 & 4 & \multirow{3}{*}{5} \\
\hline & Sensibilidad & 4 & \multirow{2}{*}{5} & \\
\hline & Lesiones de la mucosa & 5 & & \\
\hline
\end{tabular}

Cuidados perineales

- Valorar/turno: piel perianal

- Higiene de la zona después de cada deposición y siempre que sea necesario

- Mantener la zona siempre limpia y seca 
- Riesgo de úlceras por presión (UPP) rc disminución de la movilidad y presión sobre prominencia ósea.

- Intolerancia a la actividad rc debilidad generalizada y disconfort con el esfuerzo.

- Deterioro de la integridad cutánea perianal rc frecuencia de las deposiciones.

- PC: riesgo de desequilibrio electrolítico.

De acuerdo con la taxonomía NANDA se ha priorizado el problema de colaboración "riesgo de desequilibrio hidroelectrolítico" y el diagnóstico enfermero "deterioro de la integridad cutánea perianal", a partir de los cuales se ha desarrollado un plan de cuidados reflejado en la tabla 2. La justificación de esta elección tiene como punto de partida que la GEA ha afectado de forma sustancial a la necesidad fisiológica de volumen de líquidos/electrolitos, provocándole debilidad generalizada que le dificuta la realización independiente de las ABVD. Asímismo, el deterioro de la integridad cutánea dificulta su bienestar y calidad de vida y puede favorecer a su vez, el desarrollo de una UPP ${ }^{14}$.

\section{Evolución}

Desde el día del ingreso en la unidad y hasta el alta hospitalaria una semana después, la paciente pasó de 3-4 deposiciones diarias a 1-2 y de consistencia y aspecto normal, lo que ha contribuido, junto a una higiene rigurosa, a la desaparición del eritema perianal. La situación de esta paciente se ha resuelto mediante la reposición intravenosa de líquidos y electrolitos, junto a una alimentación temprana con exclusión de leche y derivados lácteos en la que se han ido incorporando sucesivamente alimentos con fibra hasta llegar a una dieta basal con buena tolerancia. Durante los días de hospitalización y mientras permanecía sentada en el sillón, comienza a realizar ejercicios para mejorar la fuerza muscular. Esta recuperación física ha proporcionado la base para potenciar el resto de sus requisitos de autocuidado, tales como la mejora de su autoestima al recuperar su autonomía en el baño y para la higiene personal.

Ante la reanudación de la tolerancia oral y la normalización de las cifras de electrolitos, se retira la fluidoterapia intravenosa. En vísperas del alta es capaz de acudir al bańo con ayuda de un andador y supervisión, y llevar a cabo la higiene personal. Ha logrado su objetivo de realizar con ayuda las ABVD y recuperar la fuerza suficiente para volver a casa caminando.

La realización de este plan de cuidados permite, a partir de la metodología enfermera y con un lenguaje disciplinar, abordar una situación de salud derivada de un problema de colaboración, como es el caso de la GEA en las personas de mayor edad

\section{Conflicto de intereses}

Las autoras declaran no tener ningún conflicto de intereses.

\section{- BIBLIOGRAFÍA}

1. Yalda Lucero A. Etiology and management of acute infectious gastroenteritis in children and adults. Revista Médica Clínica Las Condes. 2014;25:3:463-72. https://doi.org/10.1016/S07168640(14)70063-X

2. Sansone S, Aschbacher R, Staffler M, Bombonato M, Girardi F, Larcher C, et al. Nosocomial diarrhoea in adult medical patients: the role of Clostridium difficile in a North Italian acute care teaching hospital. J Prev Med Hyg. [Internet]. 2009 [citado 8 de julio de 2019];50(2):117-20. Disponible en: https://www.ncbi.nlm.nih gov/pubmed/20099443

3. Díaz T Janepsy, Solari G Verónica, Cáceres C Omar, Mena A Javier, Baeza P Silvia, Muñoz U Ximena et al. Brote de gastroenteritis aguda en la Región de Antofagasta, Chile: 2010. Rev. chil. infectol. [Internet]. 2012 [citado 8 de julio de 2019];29(1):19-25. http:// dx.doi.org/10.4067/S0716-10182012000100003

4. Bielsa-Fernández MV, Frati-Munarib AC, Ariza-Andraca R. Tratamiento a pacientes con diarrea aguda: encuesta a un grupo de médicos generales de México: 2016. Atención Familiar [ln- ternet]. 2016;23(4):119-24. [citado 8 de julio de 2019]. Disponible en: https://www.sciencedirect.com/science/article/pii/ S1405887116301456 https://doi.org/10.1016/j.af.2016.10.002

5. Betés M, Muñoz Navas M. Protocolo diagnóstico y tratamiento de la gastroenteritis aguda. Medicine. [Internet]. 2016 [citado 8 de julio de 2019];12(3):147-51. Disponible en: https://www.sciencedirect.com/ journal/medicine-programa-de-formacion-medica-continuada-acreditado/vol/12/issue/3

6. De Miguel Durán F, Perdomo Giraldi M. Gastroenteritis aguda Deshidratación. Pediatr Integral. [Internet]. 2011 [citado 8 de julio de 2019];XV(1):54-60. Disponible en: https://www.pediatriaintegral.es/wp-content/uploads/2012/03/Pediatria-Integral-XV-1. pdf\#page $=46$

7. Marcos Espino MP, Tizón Bouza E. Aplicación del Modelo de Dorothea Orem ante un Caso de una Persona con Dolor Neoplásico. Gerokomos. 2013;24(4):168-77.

8. Cuevas R, Rodríguez K, Muñiz V, Castro V, Maturell M. Enfermedad diarreica aguda en niños guatemaltecos menores de 5 años.
MEDISAN. [Internet]. 2014 [citado 8 de julio de 2019]:18(11):151523. Disponible en: http://scielo.sld.cu/scielo.php?script=sci_arttext\&pid=S1029-30192014001100005

9. NANDA. North American Nursing Diagnosis Association. Herdman T, Kamitsuru SH. Diagnósticos enfermeros. Definiciones y clasificación 2015-2017. Madrid: Elsevier España; 2017.

10. Moorhead S, Johnson M, Maas M, Swanson E. Nursing Outcomes Classification (NOC) - E-Book. 6. ${ }^{\text {a }}$ ed. Philadelphia: Mosby; 2018.

11. Butcher H, Bulechek G, McCloskey Dochterman J, Wagner C Nursing Interventions Classification (NIC) - E-Book. 7. a ed. Philadelphia: Mosby: 2018

12. Orem D. Modelo de Orem. Conceptos de Enfermería en la práctica. Barcelona: Masson-Salvat Enfermería; 1993.

13. Sttratton RJ, Hackston A, Longmore D, Dixon R, Price S, Stroud M, et al. Malnutrition in hospital outpatients and inpatients: prevalence, concurrent validity and ease of use of the "malnutrition universal screening tool" (MUST) for adults. Br J Nutr. 2004;92:799-808.

14. Norton D. Norton revised risk scores. Nursing Times. 1987:83(41):6. 